\title{
Targeted structure modification of layered silicates
}

\author{
A. M. Gerasimov, A. V. Arsentyev, 0. V. Eremina
}

REC «Mekhanobr-Tekhnika», St. Petersburg; gerasimov_am@mtspb.com

Layered silicates, the bulk of which are clay minerals, are associated with numerous mineral deposits, as they account for about $50 \%$ of the volume of all sedimentary rocks [1]. Anisotropic and highly dispersed mineral particles are formed during their disintegration. They affect adsorption and rheological properties of aqueous suspensions, which are used at processing [2]. A promising direction of intensification of concentration of ores containing layered silicates is thermal modification, which reduces negative impact of layered silicates on the main technological operations by changing the physical and chemical properties of clay component of material. The main goal - $f$ thermal modification of layered silicates is to change the microstructure of substances by sequentially removing adsorbed, interlayer (bound) and crystallization water.

Nature of the behavior of layered silicates in suspensions directly depends not only on the mineral composition of substance, but also is determined by the structure (shape) of particles [3]. By the degree of influence on dynamic viscosity of suspensions, the particles are arranged in following order: needle-shaped (montmorillonite) > flat (illite) > granular (kaolinite) > round (quartz) [1]. Therefore, distribution of indicators such as adsorption capacity and porosity of material will be identical. Tature of the changes that clays undergo during heating will be determined by mineral composition of substance. Mobile lattice of layered silicates with highly hydrophilic properties is able to release water, reducing interlayer distance during heating as actively as it absorbs during formation of suspensions. Particles exhibiting hydrophobicity, such as talc, do not undergo phase transformations to extent that can be observed in hydrophilic minerals. Transformation of heated clays can be divided into four stages: lowtemperature and high-temperature dehydration, lattice rearrangement, and high-temperature changes.

Type of heating used significantly affects change in structure of layered silicates. These types include: convective, radiation-thermal heating method [4], microwave technology. Microwave heating, in contrast to traditional heating systems, is carried out by converting electromagnetic energy into thermal energy inside material, spreading throughout volume [5]. This mechanism allows you to remove moisture from clay materials evenly, affecting the deeper layers at relatively low temperatures, minimizing time and energy costs.

Conducted experimental studies prove that montmorillonite, illite and kaolin, possessing high adsorption ability, lend themselves well to microwave radiation, in contrast to aluminosilicates such as nepheline, silicates such as quartz and feldspars. Talc, in turn, does not undergo significant changes during microwave processing, as it has hydrophobic properties, is not capable of swelling and does not dehydrate at low temperatures. A change in the structure of talc begins to occur at temperatures above $900{ }^{\circ} \mathrm{C}$ [6]. The maximum dehydration effect of montmorillonite, illite, and kaolin during microwave processing is achieved over a 5-10 min time period; further exposure to radiation reduces the adsorption capacity of minerals (Figure). The adsorption capacity of layered silicates during con- 


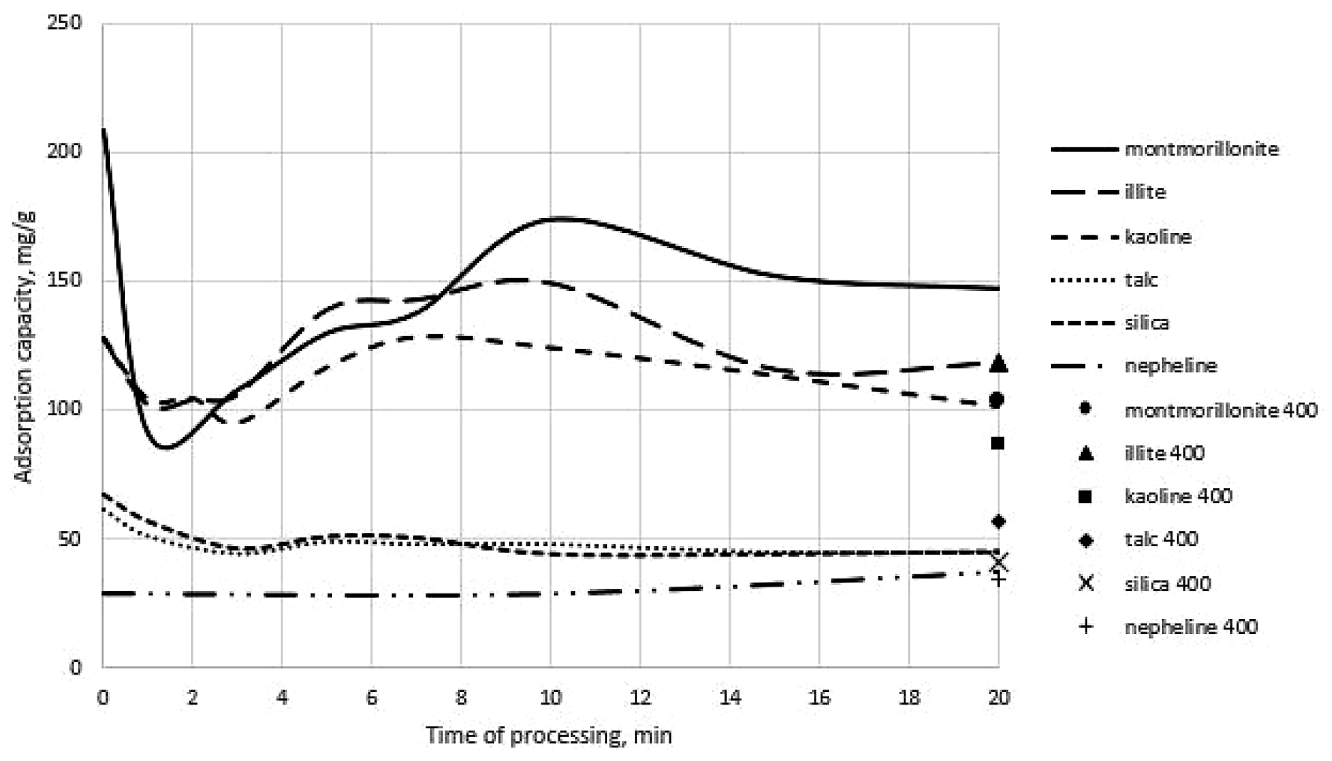

Change in the adsorption capacity of silicates depending on the processing time

vective treatment at $400{ }^{\circ} \mathrm{C}$ is lower, which makes it possible to use microwave processing of ores at the stage of enrichment for their further processing.

\section{References}

1. Gerasimov A. M., Arsentiev V. A. Layered silicates and their influence on mineral processing // Obogashcheniye rud. 2018. № 5. P. 22-28.

2. Gerasimov A. M., Lazareva V. V., Arsentiev V. A. Features of microwave heating on the properties of layered silicates // Obogashcheniye rud. 2019. № 6. P. 15-19.

3. Fedorin R. P., Khramchenkov M. G. Clay swelling and solution filtration in clays // Uchenyye zapis- ki kazanskogo gosudarstvennogo universiteta. Vol. 152. Natural sciences. 2010.

4. Kotova O. B., Razmyslov I. N., Rostovtsev V. I. Silaev V. I. Radiation-thermal modification of ferruginous bauxites in the processes of their processing // Obogashcheniye rud. 2016. № 4. P. 16-23.

5. Singh S., Gupta D., Jain V., Sharma A.K. Microwave processing of materials and applications in manufacturing industries: A review // Materials and Manufacturing Processes. 2015. v. 30, p. $1-29$ doi: $10.1080 / 10426914.2014 .952028$

6. Yakovleva A. A., Chyong S. N. The study of the absorption capacity of talc // VESTNIK IrGTU. № 5. 2010. P. $224-229$. 